\title{
Does Excess Tissue Sodium Storage Regulate Blood Pressure?
}

\author{
Giacomo Rossitto ${ }^{1,2} \cdot$ Christian Delles $^{1}[$
}

Accepted: 3 February 2022 / Published online: 22 February 2022

(c) The Author(s) 2022

\begin{abstract}
Purpose of Review The regulation of blood pressure is conventionally conceptualised into the product of "circulating blood volume" and "vasoconstriction components". Over the last few years, however, demonstration of tissue sodium storage challenged this dichotomous view.

Recent Findings We review the available evidence pertaining to this phenomenon and the early association made with blood pressure; we discuss open questions regarding its originally proposed hypertonic nature, recently challenged by the suggestion of a systemic, isotonic, water paralleled accumulation that mirrors absolute or relative extracellular volume expansion; we present the established and speculate on the putative implications of this extravascular sodium excess, in either volumeassociated or -independent form, on blood pressure regulation; finally, we highlight the prevalence of high tissue sodium in cardiovascular, metabolic and inflammatory conditions other than hypertension.

Summary We conclude on approaches to reduce sodium excess and on the potential of emerging imaging technologies in hypertension and other conditions.
\end{abstract}

Keywords Tissue sodium $\cdot$ Blood pressure $\cdot$ Hypertension $\cdot$ Volume $\cdot$ Blood vessels

\section{Laragh's Volume-Vasoconstriction Approach to Understanding Hypertension}

A radically simple, "reductionist" view of the circulation would regard it as a system where a pump (heart) supplies a fluid (blood) via a tube (blood vessels) to the periphery (organs, tissues) [1]. In this model, Darcy's law identifies blood flow $(Q)$ as the difference in pressure across the system $(\Delta P$, conveniently simplified to systemic arterial blood pressure given the trivial contribution of venous pressure to $\Delta P$ value) divided by resistance $(R)$ [2]. Accordingly, blood pressure is determined by the product of the flow through the systemic circulation, i.e. cardiac output (including elements

This article is part of the Topical Collection on Hypertension and the Kidney

Christian Delles

Christian.Delles@glasgow.ac.uk

1 Institute of Cardiovascular and Medical Sciences, BHF Glasgow Cardiovascular Research Centre, University of Glasgow, 126 University Place, Glasgow G12 8TA, UK

2 Department of Medicine (DIMED), University of Padua, Padua, Italy of volume and cardiac performance in its definition), and total peripheral resistance.

This equation underwent clinical conceptualisation by John Laragh who identified sodium $\left(\mathrm{Na}^{+}\right)$, aldosterone and the kidneys contributing to "circulating blood volume"; and angiotensin and non-angiotensin vasoconstricting factors contributing to "vasoconstrictor components" [3, 4].

This concept provides a rational approach to contemporary antihypertensive therapies in the vast majority of patients, "as incontrovertible as the laws of physics" [5]. With the exception of the so-called decapitated hypertension, characterised by a reduction in blood pressure values independent of treatment and secondary to an overt reduction in ventricular function [6], the contribution of "cardiac performance" to the equation can generally be neglected and hypertension be treated with agents targeting its volume (mainly diuretics) or vasoconstriction (e.g. calcium channel blockers, ACE-inhibitors, $\mathrm{AT}_{1}$-receptor blockers) components, or a combination of them. In fact, current guidelines tend to favour early use of combination therapies that address more than one primary mechanism [1, 7] and reflect the multifactorial Mosaic view of hypertension pathogenesis, first proposed by Page [8] and recently reviewed and expanded by Harrison et al. [9]. Irrespective of 
current therapeutic pragmatism, the volume-vasoconstriction framework remains pathophysiologically valid, whereby the different components of the mosaic - no matter how complicated - would eventually impact one or the other aspect. Validity is such that polarisation of views [10] and overt controversy between renal and vascular "dysfunctionists" for the primacy of pathogenic mechanisms remain vivid $[11,12]$.

In the last few years, however, a novel aspect emerged that puzzlingly eludes Laragh's dichotomous approach: the idea of tissue sodium storage. $\mathrm{Na}^{+}$, the leading player in the "volume" chapter of the story, has been suggested to accumulate in the extravascular compartment (i.e. out of the "tubes" and more precisely in the interstitial space, according to the original and ongoing conceptualisation) in animal models $[13,14,15 \bullet \bullet]$ and patients with arterial hypertension $[16,17]$. The question as to whether excess tissue sodium regulates blood pressure, as discussed in this review, naturally arises from this novel evidence.

\section{Description of Tissue $\mathrm{Na}^{+}$Accumulation and Its Association with Hypertension}

Although it was first suggested by Russian investigators in the 1970s [18], the concept of tissue $\mathrm{Na}^{+}$was more fully developed by Jens Titze and co-workers over the last 20 years. In keeping with previous evidence of positive $\mathrm{Na}^{+}$balance without commensurate water retention or body weight increases in subjects on short-term high salt diet [19], they reported a dissociation between $\mathrm{Na}^{+}$and weight changes in unique long-term (months) observational [20] and interventional [21] studies, thus supporting the idea of a body reservoir for nonosmotic water-free sodium storage. Rat body-composition studies [14, 22-24] and ${ }^{23} \mathrm{Na}$-magnetic resonance imaging (MRI) in humans [16] pointed to the skin, and to some extent the muscle, as the specific depots for excess $\mathrm{Na}^{+}$accumulation, with the negatively charged glycosaminoglycans (GAGs) network serving as the dynamically regulated substrate for putative interstitial skin $\mathrm{Na}^{+}$binding [25].

The long-established association between salt and hypertension made hypertensive rodent models and patients with hypertension the most obvious targets to investigate the biological relevance of the phenomenon. Indeed, salt-sensitive rats exhibited excess skin $\mathrm{Na}^{+}$retention upon salt-loading, paralleled by water $[13,22]$ but not to the point of iso-osmotically matching $\mathrm{Na}^{+}$positive balance [14], and hypertensive patients with refractory hypertension or primary aldosteronism had increased tissue $\mathrm{Na}^{+}$content compared with normotensive controls [17] or post-adrenalectomy follow-up [16], respectively. From these data, one can draw one first (\#1) conclusion: hypertension, particularly, salt-sensitive hypertension, is associated with tissue $\mathrm{Na}^{+}$accumulation.

\section{Osmotic and Non-osmotic Tissue $\mathrm{Na}^{+}$ in Hypertension}

The first rodent studies suggested that a reduced osmotically inactive (i.e. water-independent) $\mathrm{Na}^{+}$storage capacity upon salt-loading would confer salt-sensitivity of blood pressure via excess fluid retention [13]; if so, $\mathrm{Na}^{+}$accumulation would be a beneficial buffering phenomenon to prevent volume excess. This idea was supported by a study in young (mean $30 \pm 2$, range: 18-49 years) healthy subjects randomised to a low $\mathrm{Na}^{+}$diet $(70 \mathrm{mmol} /$ day) plus placebo or slow sodium ( $200 \mathrm{mmol} /$ day) tablets for 7 days: skin $\mathrm{Na}^{+} /$ $\mathrm{K}^{+}$increased between placebo and slow sodium phases, although the change reached significance only in men and not women. The latter, at variance, experienced an increase in $24 \mathrm{~h}$ mean blood pressure (BP) [26].

Laffer et al. found salt-resistant (SR) and salt-sensitive (SS) normotensive subjects to exhibit similar $\mathrm{Na}^{+}$balance during a protocol of salt-loading and depletion, but SR did not gain weight during $\mathrm{Na}^{+}$retention whereas SS did [27]; remarkably, SS also failed to reduce their total peripheral resistance in response to salt loading (see below). An independent report recently suggested that healthy individuals could also store and "osmotically inactivate" significant amounts of sodium after hypertonic saline infusion [28]. While these studies lacked any direct assessment of skin water and electrolytes, these findings overall suggest that tissue $\mathrm{Na}^{+}$buffering would reduce the adverse haemodynamic consequences of loading, i.e. (\#2a) osmotic, but not non-osmotic, $\mathrm{Na}^{+}$accumulation is associated with hypertension. Of course, association is not causation. Notably, ${ }^{23} \mathrm{Na}$-MRI skin signal did strongly and independently correlate with BP and left ventricular mass in patients with mild to moderate chronic kidney disease, but "similar associations were found for [MRI] skin water measurements" [29]. Is water the "bad" here, then?

In fact, results from seminal studies from the original proponents of the non-osmotic $\mathrm{Na}^{+}$concept somehow challenged the above. In rats treated with high-salt diet, skin $\mathrm{Na}^{+}$accumulation without reported commensurate water retention was paralleled by an increase in arterial BP. Inhibition of the VEGF-C signalling (induced by the tonicityresponsive enhancer binding protein [TonEBP] in interstitial mononuclear cells and shown to trigger expansion of the lymphatic network as a local $\mathrm{Na}^{+}$draining system), as well as selective TonEBP deletion, augmented interstitial $\mathrm{NaCl}$-to-water accumulation and elevated blood pressure in response to high-salt diet $[23,24]$. Therefore, $(\# 2 b)$ lack of non-osmotic $\mathrm{Na}^{+}$(and/or $\mathrm{Cl}^{-}$) clearance from tissues is associated with SS hypertension. Once again, in the absence of specific approaches targeting tissue-only $\mathrm{Na}^{+}$excess, and ideally only its proposed non-osmotic component, association is not causation. 


\section{A View Alternative to the Non-osmotic Compartment}

The above conclusions on osmotic and non-osmotic interstitial $\mathrm{Na}^{+}$may appear conflicting. Moreover, how does the proposed non-osmotic interstitial $\mathrm{Na}^{+}$elude parallel water accrual while simultaneously driving TonEBP-mediated signalling? Notably, our recent body-composition study in SS and SR rats failed to confirm any hypertonic tissue $\mathrm{Na}^{+}$accumulation [30••]. While tissue $\mathrm{Na}^{+}$content and concentration did increase with high-salt diet, the findings were interpreted in light of a whole-tissue histochemical deductive approach [31-33] and appeared in keeping with a prediction model based on the extracellularto-intracellular composition of tissues [34•]. In hypertensive patients, as in rats, skin $\mathrm{Na}^{+}$excess was isotonic; tissue water, $\mathrm{Na}^{+}$and $\mathrm{Na}^{+} / \mathrm{K}^{+}$ratio were associated with pulse pressure,

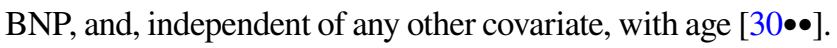
Consistently, a close correlation between human skin $\mathrm{Na}^{+}$and water had already been independently reported [35]. Overall, the conclusions are that (\#3) tissue $\mathrm{Na}^{+}$excess is systemic and reflects extracellular volume (ECV) expansion compared to the intracellular (ICV), with or without an oedematous component. In fact, even the seminal studies reported that excess $\mathrm{Na}^{+}$accumulation was accompanied by reduced ICV [23].

The proposition \#3 brings the focus back to the volume extreme of the original dichotomic approach. Please note that ECV expansion does not equal intravascular volume expansion: upon salt-loading, after an "initiation" phase, the transient increase in cardiac output in both SS and SR subjects tends to resolve and cardiac output returns to normal or nearly normal values [36]. Moreover, there are subsets of hypertensive patients who have lower, rather than higher, plasma volume than normal subjects, and hypertensives as a group tend to have low plasma to interstitial fluid volume ratio, indicating that extracellular fluid distribution between the intravascular and interstitial compartments is largely shifted toward the latter [37-39].

On the other hand, why would ICV reduce? This may represent a relative reduction in face of an expanded ECV, but also active plasticity of the body cellular mass to accommodate (isotonic) excess $\mathrm{Na}^{+}$while free water is excreted via renal or non-renal $[40,41,42 \bullet]$ routes, as already suggested [43]; alternatively, it could be the passive result of a saltinduced catabolic state [44-46]. Both would point again to water, and not only $\mathrm{Na}^{+}$, handling as the core of the matter.

\section{A "Volume" Factor Impacting "Resistance"?}

In the economy of physics of simple pipes, and of Laragh's approach accordingly, neither a hypertonic nor a waterparalleled, but extravascular, $\mathrm{Na}^{+}$excess appears to directly impact the cardiac output/intravascular volume side of the equation.

If a hypertonic accumulation in tissues is assumed, conclusion \#2b would suggest a volume-independent effect of interstitial $\mathrm{Na}^{+}$on arterial function. In cell culture experiments, supraphysiologic $\mathrm{Na}^{+}$concentrations in the medium were shown to induce early changes in protein turnover and cellular hypertrophy of vascular smooth muscle cells [47]; however, ex vivo exposure of rat resistance vessels to hypertonic $\mathrm{Na}^{+}$concentrations did not induce hypertensive hypercontractility or impaired relaxation [30••]. Still, lack of direct $\mathrm{Na}^{+}$-mediated vascular dysfunction does not exclude indirect effects: high $\mathrm{Na}^{+}$has been independently shown to modulate the cells of the immune system and to induce a proinflammatory phenotype, as reviewed in

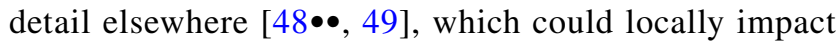
vascular - and particularly endothelial [50,51] - function. Whether any such hypertonic $\mathrm{Na}^{+}$niche is actually encountered by immune cells in human pathophysiology remains to be proven, but even microscopic gradients (e.g. on the endothelial surface) [52•] in the absence of whole tissue hypertonicity could possibly suffice [43].

If one accepts the idea of the overall isotonicity of tissue $\mathrm{Na}^{+}$, instead, syllogisms are not easier: this "volume" would still be outwith the pipes. However, whether ECV expansion is due to extracellular matrix remodelling or to excess interstitial fluid, an impact on vascular function is conceivable. In the first case, hypertensive organ damage that includes changes in the interstitial matrix [53] and vascular fibrosis would per se result into excess ECV (and therefore tissue $\mathrm{Na}^{+}[34 \bullet]$ ), would determine vascular stiffness and would raise BP accordingly. In the second case, with clinical or subclinical oedema, even microscopic excess of intercellular fluid in the vascular wall could disturb organ function, i.e. stiffen the vessels and increase

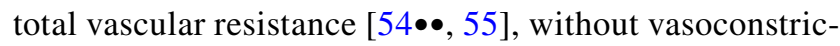
tion sensu stricto. This contention, still awaiting confirmation, is in keeping with the hemodynamic characteristics of sodium-sensitive human subjects [27,56], with the correlation between skin $\mathrm{Na}^{+} / \mathrm{K}^{+}$ratio and peripheral vascular resistance [26] or pulse pressure [30••], as well as with functional impairment in the myocardium of hypertensive dogs $[57,58]$. Moreover, accumulation of fluids even "outside" the vascular wall in the most peripheral interstitium would affect local biophysical homeostasis $[59,60]$ and possibly increase total vascular resistance by inducing at least functional, if not anatomical, microvascular and capillary rarefaction. Of note, many cell signalling pathways activated by dietary salt were previously described as "reminiscent of cell mechanoreceptor signalling" [50]: a not necessarily vascular volume expansion would nicely explain so. 
In summary, the idea of interstitial tissue $\mathrm{Na}^{+}$, either osmotic or non-osmotic, largely eludes a simplistic intravascular volume/vasoconstriction conceptualisation (Fig. 1) because (\#4) human circulation is far from being a closed system of simple pipes.

\section{Would Targeting Tissue $\mathrm{Na}^{+}$Improve Resistance?}

An epidemiological association between altered arterial compliance and distensibility with high-salt diet, ultimately resulting in increased vascular resistance, has been suggested long ago [61]. However, more direct evidence in support of the above contentions should refer to tissue, rather than dietary, $\mathrm{Na}^{+}$and to strategies that are known to reduce its accumulation. While enhancers of the lymphangiogenic response that provides interstitial drainage $[23,24]$ are still out of sight, different classes of natriuretic agents have consistently shown potential in this regard. Mineralocorticoid receptor antagonists (MRA) [16, 62•], loop diuretics [63], as well as the novel sodium-glucose co-transporter-2 (SGLT2) inhibitors [64] were all shown to reduce tissue $\mathrm{Na}^{+}$content by means of ${ }^{23} \mathrm{Na}-\mathrm{MRI}$.

Classic diuretics in the treatment of hypertension are often considered to have little or no effect on vascular health. Despite this assumption, thiazide and thiazide-like diuretics are in fact as effective as calcium channel blockers and angiotensin receptor blockers in reducing arterial stiffness and central pressure [65-67]. As these beneficial effects do not include improvements in endothelial function [68-70], a direct effect on vascular mechanics via reduction in tissue $\mathrm{Na}^{+}$seems plausible. Of note, the secondary increase in plasma aldosterone upon diuretic treatment might in part counteract the effects of these drugs [71], thereby supporting the use of diuretics as part of a combination strategy with renin-angiotensin-aldosterone blockers [7].

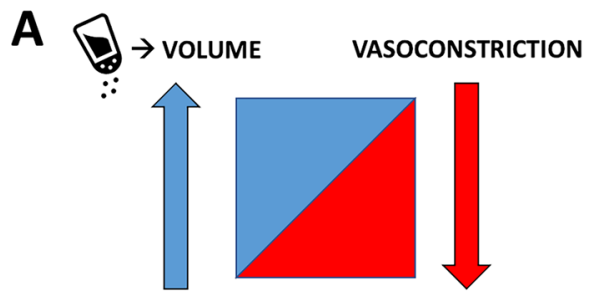

Fig. 1 Sodium and regulation of blood pressure: classic and novel perspectives. A The vasoconstriction-volume spectrum of clinical hypertension (ref 4); $\mathrm{Na}^{+}$(salt shaker) is considered the main determinant of the "intravascular volume" extreme of the spectrum, which variably combines with the independent "vasoconstriction" extreme to sustain different forms of high blood pressure (BP). B The current understanding of tissue $\mathrm{Na}^{+}$accumulation expands beyond the vascular bed. Water-paralleled (osmotic) interstitial $\mathrm{Na}^{+}$, in equilibrium
MRAs even outperform other diuretics in improving arterial stiffness [72]. Their beneficial effects extend to endothelium-dependent flow-mediated vasodilatation [73], likely due to the role of MR in the modulation of endothelial stiffness and function [51, 74, 75•], and to highly specialised vascular beds such as coronary circulation $[76,77]$. The novel nonsteroidal and highly selective finerenone, with recently demonstrated impact on hard cardiovascular outcomes in patients with chronic kidney disease and type 2 diabetes [78], seems to feature similar beneficial properties via structural remodelling of resistance vessels [79], potentially in keeping with the idea of

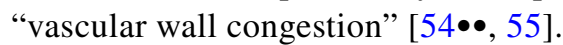

SGLT2 inhibitors are novel antidiabetic agents that showed large and unexpected cardiovascular protection in multiple outcome trials, via mechanisms largely beyond glycaemic control and including early natriuresis [80]. Like the "cognate" natriuretic agents above, they were reported to reduce various parameters of arterial stiffness [81].

For the interpretation of all such evidence, particularly in relation to the pleiotropic effects of SGLT2 inhibition [80, 82], it is certainly hard to dissect the role of covariates, confounders and likely parallel mechanisms, including the distribution of excess sodium to the intracellular compartment and its consequences. However, it seems safe to state that (\#5) agents with demonstrated potential to reduce tissue $\mathrm{Na}^{+}$do exert beneficial effects on determinants of vascular resistance.

\section{Not Only Hypertension!}

The remarkable expansion of ${ }^{23} \mathrm{Na}-\mathrm{MRI}$ data in the last few years has made very clear that, in addition to patient with hypertension, excess tissue $\mathrm{Na}^{+}$signal is prevalent in a multitude of traditional cardiovascular risk factors and conditions, including heart failure [63] and chronic kidney disease [29]. After the first reports [64], patients with

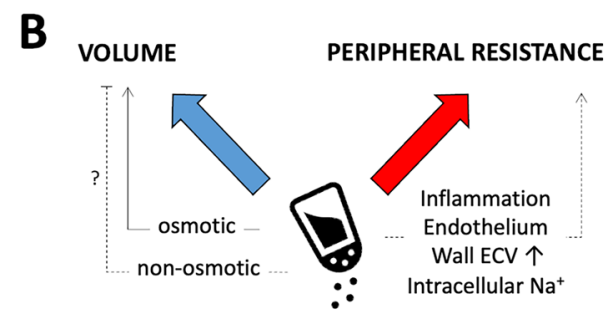

with the intravascular compartment, determines a whole-body volume excess; non-osmotic storage capacity could provide a buffering system which prevents a rise in BP, but lacks confirmation. Interstitial $\mathrm{Na}^{+}$could simultaneously impact vascular function and increase peripheral resistance by inducing a local inflammatory state, endothelial damage, water-paralleled expansion of the extracellular volume (ECV) and changes in intracellular $\mathrm{Na}^{+}$in the vascular wall 
type-2 diabetes were recently shown to accumulate even greater skin and muscle $\mathrm{Na}^{+}$than patients with primary hypertension $[83 \bullet]$.

In addition, excess tissue $\mathrm{Na}^{+}$signal was identified in the lower limbs of patients with lipedema [84•], a condition characterised by excess accumulation of adipocytes and inflammatory interstitial fluid $[85,86]$, in systemic sclerosis [87] and systemic lupus erythematosus [88]. Such evidence links the phenomenon to inflammation in general, without any direct implication on high blood pressure; this is also in keeping with high $\mathrm{Na}^{+}$signal in the brain of patients with multiple sclerosis [89]. Whether all this reflects the extravasation of fluids typical of inflammation or a primary activation of inflammatory cells by local hypertonic niches [48••], or a combination of both, remains to be established. Of note, tissue changes with less inflammatory components but similar ECV expansion, like liver fibrosis, revealed the same increase in tissue $\mathrm{Na}^{+}$signal [90, 91].

All in all, (\#6) tissue $\mathrm{Na}^{+}$accumulation appears to be a prevalent and systemic phenomenon which, as suggested, relates to acute or chronic changes in ECV distribution [34•] and - possibly - content. The implication of these changes may variably affect the different organs involved, including but not limited to blood vessels. The tremendous, although largely unexpected, beneficial effect that natriuretic agents recently showed in large cardiovascular outcome trials suggests cardiovascular implications beyond blood pressure control (43).

\section{Gaps of Knowledge and Conclusions}

In summary, all the reviewed evidence above indicates that excess tissue $\mathrm{Na}^{+}$accumulation contributes or at least relates to blood pressure control, but a radically simple "reductionist" approach to its understanding falls short in explaining much of this contribution. Laragh's concept of "intravascular volume" did not include extravascular space, and a purely "vasoconstrictor component" definition disregarded aspects of vascular biology, structure and mechanics that are possibly affected by interstitial $\mathrm{Na}^{+}$(Fig. 1).

Despite this awareness, we still face several "unknowns" in the field. The nature of the accumulation, hypertonic vs isotonic, is still debated. In case of hypertonic excess, evidence is conflicting in relation to a beneficial "buffering" function or a signature/determinant of disease, although the epidemic of high ${ }^{23} \mathrm{Na}$-MRI signal in cardiovascular and inflammatory diseases, as well as its association with organ damage, would suggest the latter. On the contrary, an isotonic (water-paralleled) ECV expansion could simultaneously be the driver and result of hypertensive hydraulic, inflammatory and fibrotic damage. An excess volume status seems indeed to accompany an increased tissue and total body sodium, but it is largely subclinical and often difficult to assess.

Of note, it is still unclear how $\mathrm{Na}^{+}$is locally handled across vascular and cellular membranes and where exactly the excess accumulation develops, or why this happens in some individuals and not as much in others. Additionally, the fact that the large majority of body $\mathrm{Na}^{+}$remains handled and excreted by the kidneys [92] leaves only a tiny signal for tissues and makes relevant investigations more challenging out of experimental settings. Similarly, the current lack of therapeutic tools targeting only interstitial $\mathrm{Na}^{+}$excess prevents specificity of conclusions.

However, the beneficial impact of different natriuretic agents in hypertension and other cardiovascular conditions is now established and could be mediated at least in part by a reduction in tissue $\mathrm{Na}^{+}$content. A wider use and the ongoing refinement of methods for its measurement [93] may facilitate better stratification of patients with hypertension, tailored reduction in salt intake and more targeted treatment.

Acknowledgements We are grateful to the British Heart Foundation for supporting our research (Centre of Research Excellence Award, $\mathrm{RE} / 18 / 6 / 34217)$.

\section{Compliance with Ethical Standards}

Conflict of Interest Giacomo Rossitto and Christian Delles declare that they have no conflict of interest.

Human and Animal Rights and Informed Consent This article does not contain any studies with human or animal subjects performed by any of the authors.

Open Access This article is licensed under a Creative Commons Attribution 4.0 International License, which permits use, sharing, adaptation, distribution and reproduction in any medium or format, as long as you give appropriate credit to the original author(s) and the source, provide a link to the Creative Commons licence, and indicate if changes were made. The images or other third party material in this article are included in the article's Creative Commons licence, unless indicated otherwise in a credit line to the material. If material is not included in the article's Creative Commons licence and your intended use is not permitted by statutory regulation or exceeds the permitted use, you will need to obtain permission directly from the copyright holder. To view a copy of this licence, visit http://creativecommons.org/licenses/by/4.0/.

\section{References}

Papers of particular interest, published recently, have been highlighted as:

- Of importance

$\bullet$ Of major importance 
1. Mary S, Rossitto G, Delles C. Pathophysiology of hypertension. In GYH NSaL, editor. Hypertension (Dallas, Tex : 1979). 3rd ed. Oxford, UK: Oxford University Press. 2021.

2. Herring NPDJ. Levick's introduction to cardiovascular physiology. Sixth ed: CRC Press Book. 2018.

3. Laragh JH. Vasoconstriction-volume analysis for understanding and treating hypertension: the use of renin and aldosterone profiles. Am J Med. 1973;55(3):261-74.

4. Laragh J. Laragh's lessons in pathophysiology and clinical pearls for treating hypertension. Am J Hypertens. 2001;14(6 Pt 1):491-503.

5. Brown MJ. Renin: friend or foe? Heart (British Cardiac Society). 2007;93(9):1026-33.

6. Messerli FH, Rimoldi SF, Bangalore S. The transition from hypertension to heart failure: contemporary update. JACC Heart Failure. 2017;5(8):543-51.

7. Williams B, Mancia G, Spiering W, Agabiti Rosei E, Azizi M, Burnier M, et al. 2018 ESC/ESH Guidelines for the management of arterial hypertension. Eur Heart J. 2018;39(33):3021-104.

8. Page IH. Pathogenesis of arterial hypertension. J Am Med Assoc. 1949;140(5):451-8.

9. Harrison DG, Coffman TM, Wilcox CS. Pathophysiology of hypertension: the mosaic theory and beyond. Circ Res. 2021;128(7):847-63.

10. Bie P, Evans RG. Normotension, hypertension and body fluid regulation: brain and kidney. Acta Physiol (Oxf). 2017;219(1):288-304.

11. Hall JE. Renal dysfunction, rather than nonrenal vascular dysfunction, mediates salt-induced hypertension. Circulation. 2016;133(9):894-906.

12. Morris RC Jr, Schmidlin O, Sebastian A, Tanaka M, Kurtz TW. Vasodysfunction that involves renal vasodysfunction, not abnormally increased renal retention of sodium, accounts for the initiation of salt-induced hypertension. Circulation. 2016;133(9):881-93.

13. Titze J, Krause H, Hecht H, Dietsch P, Rittweger J, Lang R, et al. Reduced osmotically inactive Na storage capacity and hypertension in the Dahl model. Am J Physiol Renal Physiol. 2002;283(1):F134-41.

14. Titze J, Bauer K, Schafflhuber M, Dietsch P, Lang R, Schwind $\mathrm{KH}$, et al. Internal sodium balance in DOCA-salt rats: a body composition study. Am J Physiol Renal Physiol. 2005;289(4):F793-802.

15.• Titze J, Luft FC. Speculations on salt and the genesis of arterial hypertension. Kidney Int. 2017;91(6):1324-35. This review summarises the early findings that led to the concept of hypertonic tissue environments and its association with hypertension.

16. Kopp C, Linz P, Wachsmuth L, Dahlmann A, Horbach T, Schofl $\mathrm{C}$, et al. 23Na magnetic resonance imaging of tissue sodium. Hypertension (Dallas, Tex : 1979). 2012;59(1):167-72.

17. Kopp C, Linz P, Dahlmann A, Hammon M, Jantsch J, Muller $\mathrm{DN}$, et al. 23Na magnetic resonance imaging-determined tissue sodium in healthy subjects and hypertensive patients. Hypertension (Dallas, Tex : 1979). 2013;61(3):635-40.

18. Ivanova LN, Archibasova VK, Shterental I. Sodium-depositing function of the skin in white rats. Fiziol Zh SSSR Im I M Sechenova. 1978;64(3):358-63.

19. Heer M, Baisch F, Kropp J, Gerzer R, Drummer C. High dietary sodium chloride consumption may not induce body fluid retention in humans. Am J Physiol Renal Physiol. 2000;278(4):F585-95.

20. Titze J, Maillet A, Lang R, Gunga HC, Johannes B, Gauquelin-Koch $\mathrm{G}$, et al. Long-term sodium balance in humans in a terrestrial space station simulation study. Am J Kidney Dis. 2002;40(3):508-16.
21. Rakova N, Juttner K, Dahlmann A, Schroder A, Linz P, Kopp C, et al. Long-term space flight simulation reveals infradian rhythmicity in human $\mathrm{Na}(+)$ balance. Cell Metab. 2013;17(1):125-31.

22. Titze J, Lang R, Ilies C, Schwind KH, Kirsch KA, Dietsch $\mathrm{P}$, et al. Osmotically inactive skin $\mathrm{Na}+$ storage in rats. Am $\mathrm{J}$ Physiol Renal Physiol. 2003;285(6):F1108-17.

23. Machnik A, Neuhofer W, Jantsch J, Dahlmann A, Tammela T, Machura K, et al. Macrophages regulate salt-dependent volume and blood pressure by a vascular endothelial growth factor-Cdependent buffering mechanism. Nat Med. 2009;15(5):545-52.

24. Wiig H, Schroder A, Neuhofer W, Jantsch J, Kopp C, Karlsen TV, et al. Immune cells control skin lymphatic electrolyte homeostasis and blood pressure. J Clin Investig. 2013;123(7):2803-15.

25. Titze J, Shakibaei M, Schafflhuber M, Schulze-Tanzil G, Porst $\mathrm{M}$, Schwind KH, et al. Glycosaminoglycan polymerization may enable osmotically inactive $\mathrm{Na}+$ storage in the skin. Am J Physiol Heart Circ Physiol. 2004;287(1):H203-8.

26. Selvarajah V, Maki-Petaja KM, Pedro L, Bruggraber SFA, Burling K, Goodhart AK, et al. Novel mechanism for buffering dietary salt in humans: effects of salt loading on skin sodium, vascular endothelial growth factor $\mathrm{C}$, and blood pressure. Hypertension (Dallas, Tex : 1979). 2017;70(5):930-7.

27. Laffer CL, Scott RC, 3rd, Titze JM, Luft FC, Elijovich F. Hemodynamics and salt-and-water balance link sodium storage and vascular dysfunction in salt-sensitive subjects. Hypertension (Dallas, Tex : 1979). 2016;68(1):195-203.

28. Olde Engberink RH, Rorije NM, van den Born BH, Vogt L. Quantification of nonosmotic sodium storage capacity following acute hypertonic saline infusion in healthy individuals. Kidney Int. 2017;91(3):738-45.

29. Schneider MP, Raff U, Kopp C, Scheppach JB, Toncar S, Wanner C, et al. Skin sodium concentration correlates with left ventricular hypertrophy in CKD. J Am Soc Nephrol. 2017;28(6):1867-76.

30.• Rossitto G, Mary S, Chen JY, Boder P, Chew KS, Neves KB, et al. Tissue sodium excess is not hypertonic and reflects extracellular volume expansion. Nat Commun. 2020;11(1):4222. By means of preclinical and clincial approaches, this article challenges the concept of tissue $\mathrm{Na}^{+}+$accumulation as a hypertonic phenomenon; it suggests isotonic ECV expansion as the key determinant of excess $\mathrm{Na}^{+}+$signal/content in tissues.

31. Lowry $\mathrm{OH}$, Hastings $\mathrm{AB}$. Histochemical changes associated with aging: I methods and calculations. J Biol Chem. 1942;143.

32. Lowry $\mathrm{OH}$, Hastings $\mathrm{AB}$, Hull TZ, Brown AN. Histochemical changes associated with aging: II. Skeletal and cardiac muscle in rats. $1942 ; 143$.

33. Lowry $\mathrm{OH}$, Hastings $\mathrm{AB}$, et al. Histochemical changes associated with aging; liver, brain, and kidney in the rat. J Gerontol. 1946;1(3 Pt 1):345-57.

34. Rossitto G, Touyz RM, Petrie MC, Delles C. Much Ado about N...atrium: modelling tissue sodium as a highly sensitive marker of subclinical and localized oedema. Clin Sci. 2018;132(24):2609-13. This article describes the model for the hystochemical interpretation of $\mathrm{Na}^{+}$and $\mathrm{K}^{+}$data in tissues as a function of extracellular and intracellular volume distributions.

35. Chachaj A, Puła B, Chabowski M, Grzegrzółka J, SzahidewiczKrupska E, Karczewski M, et al. Role of the lymphatic system in the pathogenesis of hypertension in humans. Lymphat Res Biol. 2018;16(2):140-6.

36. Schmidlin O, Sebastian AF, Morris Jr RC. What initiates the pressor effect of salt in salt-sensitive humans? Observations in normotensive blacks. Hypertension (Dallas, Tex : 1979). 2007;49(5):1032-9. 
37. Tarazi RC, Dustan HP, Frohlich ED. Relation of plasma to interstitial fluid volume in essential hypertension. Circulation. 1969;40(3):357-66.

38. Tarazi RC, Dustan HP, Frohlich ED, Gifford Jr RW, Hoffman GC. Plasma volume and chronic hypertension. Relationship to arterial pressure levels in different hypertensive diseases. Archives of internal medicine. 1970;125(5):835-42.

39. Tarazi RC. Hemodynamic role of extracellular fluid in hypertension. Circ Res. 1976;38(6 Suppl 2):73-83.

40. Braconnier P, Milani B, Loncle N, Lourenco JM, Brito W, Delacoste J, et al. Short-term changes in dietary sodium intake influence sweat sodium concentration and muscle sodium content in healthy individuals. J Hypertens. 2020;38(1):159-66.

41. Chen JY. Abstracts from the 2020 Annual scientific meeting of the British and Irish hypertension society (BIHS); O-04. J Hum Hypertens. 2020;34(Suppl 1):3.

42.•Wild J, Jung R, Knopp T, Efentakis P, Benaki D, Grill A, et al. Aestivation motifs explain hypertension and muscle mass loss in mice with psoriatic skin barrier defect. Acta Physiol (Oxf). 2021:e13628. Recent study, which highlights the role of a largely neglected route for water exchange, i.e. skin, in the pathogenesis of hypertension. Balance study on salt and water homeostasis thus far have almost exclusively focused on renal function.

43. Rossitto G, Delles C. Mechanisms of sodium-mediated injury in cardiovascular disease: old play, new scripts. FEBS J. 2021. (accepted for publication).

44. Rakova N, Kitada K, Lerchl K, Dahlmann A, Birukov A, Daub $\mathrm{S}$, et al. Increased salt consumption induces body water conservation and decreases fluid intake. J Clin Investig. 2017;127(5):1932-43.

45. Kitada K, Daub S, Zhang Y, Klein JD, Nakano D, Pedchenko $\mathrm{T}$, et al. High salt intake reprioritizes osmolyte and energy metabolism for body fluid conservation. J Clin Investig. 2017;127(5):1944-59.

46. Rossitto G, Maiolino G, Lerco S, Ceolotto G, Blackburn G, Mary S, et al. High sodium intake, glomerular hyperfiltration and protein catabolism in patients with essential hypertension. Cardiovasc Res. 2020.

47. Gu JW, Anand V, Shek EW, Moore MC, Brady AL, Kelly WC, et al. Sodium induces hypertrophy of cultured myocardial myoblasts and vascular smooth muscle cells. Hypertension (Dallas, Tex : 1979). 1998;31(5):1083-7.

48.• Jobin K, Müller DN, Jantsch J, Kurts C. Sodium and its manifold impact on our immune system. Trends Immunol. 2021;42(6):469-79. Extensive review on the impact of excess $\mathrm{Na}^{+}+$on the modulation of immune cells in health and disease.

49. Ruggeri Barbaro N, Van Beusecum J, Xiao L, do Carmo L, Pitzer A, Loperena R, et al. Sodium activates human monocytes via the NADPH oxidase and isolevuglandin formation. Cardiovasc Res. 2021;117(5):1358-71.

50. Feng W, Dell'Italia LJ, Sanders PW. Novel paradigms of salt and hypertension. J Am Soc Nephrol. 2017;28(5):1362-9.

51. Oberleithner H, Riethmüller C, Schillers H, MacGregor GA, de Wardener HE, Hausberg M. Plasma sodium stiffens vascular endothelium and reduces nitric oxide release. Proc Natl Acad Sci USA. 2007;104(41):16281-6.

52. Olde Engberink RHG, Selvarajah V, Vogt L. Clinical impact of tissue sodium storage. Pediatr Nephrol. 2020;35(8):137380. A recent review, offering a non-osmotic (perspective regarding tissue $\mathrm{Na}^{+}$accumulation.

53. Fischereder M, Michalke B, Schmöckel E, Habicht A, Kunisch $\mathrm{R}$, Pavelic I, et al. Sodium storage in human tissues is mediated by glycosaminoglycan expression. Am J Physiol Renal Physiol. 2017;313(2):F319-25.
54.• Tobian L Jr, Binion JT. Tissue cations and water in arterial hypertension. Circulation. 1952;5(5):754-8. An old article, first suggesting that excess $\mathrm{Na}^{+}+$and water in the vascular wall could mechanically increase peripheral resistance.

55. Tobian L, Janecek J, Tomboulian A, Ferreira D. Sodium and potassium in the walls of arterioles in experimental renal hypertension. J Clin Investig. 1961;40:1922-5.

56. Sullivan JM, Prewitt RL, Ratts TE, Josephs JA, Connor MJ. Hemodynamic characteristics of sodium-sensitive human subjects. Hypertension (Dallas, Tex : 1979). 1987;9(4):398-406.

57. Laine GA, Allen SJ. Left ventricular myocardial edema. Lymph flow, interstitial fibrosis, and cardiac function. Circ Res. 1991;68(6):1713-21.

58. Laine GA. Microvascular changes in the heart during chronic arterial hypertension. Circ Res. 1988;62(5):953-60.

59. Wiig H, Swartz MA. Interstitial fluid and lymph formation and transport: physiological regulation and roles in inflammation and cancer. Physiol Rev. 2012;92(3):1005-60.

60. Øien AH, Justad SR, Tenstad O, Wiig H. Effects of hydration on steric and electric charge-induced interstitial volume exclusion-a model. Biophys J. 2013;105(5):1276-84.

61. Messerli FH, Schmieder RE, Weir MR. Salt: a perpetrator of hypertensive target organ disease? Arch Intern Med. 1997;157(21):2449-52.

62.• Christa M, Weng AM, Geier B, Wörmann C, Scheffler A, Lehmann L, et al. Increased myocardial sodium signal intensity in Conn's syndrome detected by $23 \mathrm{Na}$ magnetic resonance imaging. Eur Heart J Cardiovasc Imaging. 2019;20(3):263-70. First human evidence of $\mathrm{Na}^{+}+$accumulation in a tissue other than dermis or skeletal muscle, in a prototypic form of salt-sensitive hypertension.

63. Hammon M, Grossmann S, Linz P, Kopp C, Dahlmann A, Garlichs $\mathrm{C}$, et al. 23Na Magnetic resonance imaging of the lower leg of acute heart failure patients during diuretic treatment. PloS One. 2015;10(10):e0141336.

64. Karg MV, Bosch A, Kannenkeril D, Striepe K, Ott C, Schneider MP, et al. SGLT-2-inhibition with dapagliflozin reduces tissue sodium content: a randomised controlled trial. Cardiovasc Diabetol. 2018;17(1):5

65. Agnoletti D, Zhang Y, Borghi C, Blacher J, Safar ME. Effects of antihypertensive drugs on central blood pressure in humans: a preliminary observation. Am J Hypertens. 2013;26(8):1045-52.

66. Mackenzie IS, McEniery CM, Dhakam Z, Brown MJ, Cockcroft JR, Wilkinson IB. Comparison of the effects of antihypertensive agents on central blood pressure and arterial stiffness in isolated systolic hypertension. Hypertension (Dallas, Tex : 1979). 2009;54(2):409-13.

67. Alem M, Milia P, Muir S, Lees K, Walters M. Comparison of the effects of diuretics on blood pressure and arterial stiffness in patients with stroke. J Stroke Cerebrovasc Dis. 2008;17(6):373-7.

68. Zhou MS, Schulman IH, Jaimes EA, Raij L. Thiazide diuretics, endothelial function, and vascular oxidative stress. J Hypertens. 2008;26(3):494-500.

69. Muiesan ML, Salvetti M, Monteduro C, Rizzoni D, Zulli R, Corbellini C, et al. Effect of treatment on flow-dependent vasodilation of the brachial artery in essential hypertension. Hypertension (Dallas, Tex : 1979). 1999;33(1 Pt 2):575-80.

70. Muiesan ML, Salvetti M, Belotti E, Paini A, Rosei CA, Aggiusti C, et al. Effects of barnidipine in comparison with hydrochlorothiazide on endothelial function, as assessed by flow mediated vasodilatation in hypertensive patients. Blood Press. 2011;20(4):244-51.

71. Matsui Y, Eguchi K, O'Rourke MF, Ishikawa J, Shimada $\mathrm{K}$, Kario K. Association between aldosterone induced by 
antihypertensive medication and arterial stiffness reduction: the J-CORE study. Atherosclerosis. 2011;215(1):184-8.

72. Ohta Y, Ishizuka A, Hayashi S, Iwashima Y, Kishida M, Yoshihara F, et al. Effects of a selective aldosterone blocker and thiazidetype diuretic on blood pressure and organ damage in hypertensive patients. Clin Exp Hypertens. 2015;37(7):569-73.

73. Yamanari H, Nakamura K, Miura D, Yamanari S, Ohe T. Spironolactone and chlorthalidone in uncontrolled elderly hypertensive patients treated with calcium antagonists and angiotensin II receptor-blocker: effects on endothelial function, inflammation, and oxidative stress. Clin Exp Hypertens. 2009;31(7):585-94.

74. Safar ME, Temmar M, Kakou A, Lacolley P, Thornton SN. Sodium intake and vascular stiffness in hypertension. Hypertension (Dallas, Tex : 1979). 2009;54(2):203-9.

75.• Wenstedt EFE, Olde Engberink RHG, Vogt L. Sodium handling by the blood vessel wall: critical for hypertension development. Hypertension (Dallas, Tex : 1979). 2018;71(6):990-6. Insightful review on the handling of sodium by the vascular wall, including the role of the glycocalyx, the effect on endothelial function and stiffness, and the barrier effect against interstitial accumulation exerted by healthy vessels.

76. Joffe HV, Kwong RY, Gerhard-Herman MD, Rice C, Feldman K, Adler GK. Beneficial effects of eplerenone versus hydrochlorothiazide on coronary circulatory function in patients with diabetes mellitus. J Clin Endocrinol Metab. 2007;92(7):2552-8.

77. Garg R, Rao AD, Baimas-George M, Hurwitz S, Foster C, Shah $\mathrm{RV}$, et al. Mineralocorticoid receptor blockade improves coronary microvascular function in individuals with type 2 diabetes. Diabetes. 2015;64(1):236-42.

78. Filippatos G, Anker SD, Agarwal R, Pitt B, Ruilope LM, Rossing P, et al. Finerenone and cardiovascular outcomes in patients with chronic kidney disease and type 2 diabetes. Circulation. 2021;143(6):540-52.

79. Gil-Ortega M, Vega-Martín E, Martín-Ramos M, GonzálezBlázquez R, Pulido-Olmo H, Ruiz-Hurtado G, et al. Finerenone reduces intrinsic arterial stiffness in Munich Wistar Frömter rats, a genetic model of chronic kidney disease. Am J Nephrol. 2020;51(4):294-303.

80. Cowie MR, Fisher M. SGLT2 inhibitors: mechanisms of cardiovascular benefit beyond glycaemic control. Nat Rev Cardiol. 2020;17(12):761-72.

81. Striepe K, Jumar A, Ott C, Karg MV, Schneider MP, Kannenkeril $\mathrm{D}$, et al. Effects of the Selective sodium-glucose cotransporter 2 inhibitor empagliflozin on vascular function and central hemodynamics in patients with type 2 diabetes mellitus. Circulation. 2017;136(12):1167-9.

82. Marton A, Kaneko T, Kovalik JP, Yasui A, Nishiyama A, Kitada K, et al. Organ protection by SGLT2 inhibitors: role of metabolic energy and water conservation. Nat Rev Nephrol. 2021;17(1):65-77.

83. Kannenkeril D, Karg MV, Bosch A, Ott C, Linz P, Nagel AM, et al. Tissue sodium content in patients with type 2 diabetes mellitus. J Diabetes Complications. 2019;33(7):485-9.

84. Crescenzi R, Donahue PMC, Petersen KJ, Garza M, Patel N, Lee C, et al. Upper and lower extremity measurement of tissue sodium and fat content in patients with lipedema. Obesity (Silver Spring). 2020;28(5):907-15. These two recent articles suggest that excess tissue $\mathrm{Na}^{+}+$is not specific to hypertension.

85. Buso G, Depairon M, Tomson D, Raffoul W, Vettor R, Mazzolai L. Lipedema: a call to action! Obesity (Silver Spring). 2019;27(10):1567-76.

86. Lohrmann C, Foeldi E, Langer M. MR imaging of the lymphatic system in patients with lipedema and lipo-lymphedema. Microvasc Res. 2009;77(3):335-9.

87. Kopp C, Beyer C, Linz P, Dahlmann A, Hammon M, Jantsch J, et al. $\mathrm{Na}+$ deposition in the fibrotic skin of systemic sclerosis patients detected by $23 \mathrm{Na}$-magnetic resonance imaging. Rheumatology (Oxford). 2017;56(4):556-60.

88. Carranza-León DA, Oeser A, Marton A, Wang P, Gore JC, Titze $\mathrm{J}$, et al. Tissue sodium content in patients with systemic lupus erythematosus: association with disease activity and markers of inflammation. Lupus. 2020;29(5):455-62.

89. Petracca M, Vancea RO, Fleysher L, Jonkman LE, Oesingmann $\mathrm{N}$, Inglese $\mathrm{M}$. Brain intra- and extracellular sodium concentration in multiple sclerosis: a 7 T MRI study. Brain : a journal of neurology. 2016;139(Pt 3):795-806.

90. Lindquist DM, Fugate EM, Wang J, Sharma A, Gandhi CR, Dillman JR. MRI measures of murine liver fibrosis. J Magn Reson Imaging. 2021.

91. Zaric O, Juras V, Szomolanyi P, Schreiner M, Raudner M, Giraudo C, et al. Frontiers of sodium MRI revisited: from cartilage to brain imaging. J Magn Reson Imaging. 2021;54(1):58-75.

92. Lerchl K, Rakova N, Dahlmann A, Rauh M, Goller U, Basner $\mathrm{M}$, et al. Agreement between 24-hour salt ingestion and sodium excretion in a controlled environment. Hypertension (Dallas, Tex : 1979). 2015;66(4):850-7.

93. Gast LV, Völker S, Utzschneider M, Linz P, Wilferth T, Müller M, et al. Combined imaging of potassium and sodium in human skeletal muscle tissue at 7 T. Magn Reson Med. 2021;85(1):239-53.

Publisher's Note Springer Nature remains neutral with regard to jurisdictional claims in published maps and institutional affiliations. 